\title{
X-linked Charcot-Marie-Tooth disease type 4
}

INSERM

\section{Source}

INSERM. (1999). Orphanet: an online rare disease and orphan drug data base. $\underline{X \text {-linked }}$ Charcot-Marie-Tooth disease type 4. ORPHA:101078

X-linked Charcot-Marie-T ooth disease type 4 is a rare, genetic, axonal, peripheral sensorimotor neuropathy characterized by an X-linked recessive inheritance pattern and the neonatal- to early childhood-onset of severe, slowly progressive, distal muscle weakness and atrophy (in particular of the peroneal group), as well as sensory impairment (with the lower extremities being more affected than the upper extremities), pes cavus, areflexia and hammertoes. Sensorineural hearing loss and cognitive impairment may also be associated. Females are asymptomatic and do not display the phenotype. 